\title{
FOAMED CEMENT COMPOSITES: DETECTION OF THE MODULUS OF ELASTICITY USING DIC ANALYSIS AND COMPARISON WITH OTHER METHODS
}

\author{
JAKUB ĎUREJE ${ }^{a, *}$, ZDENĚK PROŠEK ${ }^{a, b}$ \\ ${ }^{a}$ Czech Technical University in Prague, Faculty of Civil Engineering, Thákurova 7, 166 29 Prague 6, Czech \\ Republic \\ ${ }^{b}$ University Centre for Energy Efficient Buildings, Czech Technical University in Prague, Třinecká 1024, \\ 27343 Buštěhrad, Czech Republic \\ * corresponding author: jakub.dureje@fsv.cvut.cz
}

Abstract. A modulus of elasticity was determined for eight differently foamed cement paste samples. Samples were loaded in the laboratory by a hydraulic press. The force acting on the sample was read directly from the laboratory press. Digital Image Correlation (DIC) analysis were used to draw deformations. Before loading pressure test was applied a random contrast pattern to the samples. Samples were captured by the camera in a one-second interval during the loading pressure test. The images were edited in the Adobe Photoshop Lightroom and then evaluated using Ncorr software. The result is a vertical and horizontal shift field. On the basis of the results obtained, it was possible to calculate the modulus of elasticity of each sample.

KEYWORDS: DIC analysis, foamed cement paste, field of displacement, static modulus of elasticity, dynamic modulus of elasticity.

\section{INTRODUCTION}

There are many different methods to detect deformation of the sample during the loading pressure test. The displacement of the crosspiece of the hydraulic press does not correspond to the deformation of the sample in the direction of the force. This is due to the deformation of the exponed parts of the test device. To measure deformations, it is possible to use some type of extensometer and place it directly between the jaws of the press in which the sample is tested and measure the displacement directly between the jaws. Thanks to the ever-improving technologies, we can obtain the entire field of displacement by DIC analysis by capturing a series of photos during sample testing and subsequent evaluation. The advantage is that, compared to the measurement with an extensometer, we obtain deformations in all directions on the measured surface of the sample [1, 2,

DIC analysis is used in many industries, by many companies, including Airbus, AWE, Stresscraft and British Energy. It is used, for example, for measuring the heat dissipation and curvature of electronic components, for measuring the $3 \mathrm{D}$ shape of the air bags, for monitoring the components of the power plants to determine their status and to reduce their emissions, or for the behavior of building materials during the loading tests [2].

DIC analysis is an optical method, to get the most accurate results it is necessary to avoid optical defects. For each lens, the image is distorted towards the edges. Depending on the deformation of the square, we distinguish distortions to barrel distortions, pincushion distortions, or a combination of both - wave distortions. Lens manufacturers are trying to eliminate these phenomena with the appropriate lens system. The lenses are constructed at certain distances where the distortion occurs least. For this reason, it is necessary to select a suitable lens and capture distance according to the size of the subject to be sensed [3, 4].

\section{MATERIALS AND SAMPLES}

The sample properties were measured at 28 days of age and the day after manufacture the samples were removed from formwork and stored freely in a laboratory environment at a temperature of $22 \pm 1{ }^{\circ} \mathrm{C}$ and a relative humidity of $50 \pm 2 \%$. Test beams of dimensions $40 \times 40 \times 160 \mathrm{~mm}$ were made, which were broken in half during the previous bend test. The reference mixtures for testing were made of Portland cement CEM I 42.5R Radotin (RefC), a combination of Portland cement and finely ground concrete recyclate in a ratio of 0.66 : 0.34 (RefR). Fine-grained recycled concrete was produced by high-speed grinding, from waste generated from drainage concrete blocks. Subsequently, the reference mixtures were lightened using foaming additives such as industrial additive from the Mapei (M) company or the additive used by firefighters $(\mathrm{H})$. The composition of the individual samples and the bulk density are given in Table 1,5 .

\section{EXPERIMENTAL METHODS}

DIC analysis was performed on a total of 10 samples, on two references and eight differently foamed cement pastes. Samples were loaded in the laboratory by a 


\begin{tabular}{|c|c|c|c|c|c|c|c|c|c|c|}
\hline $\begin{array}{c}\text { Sample } \\
\text { Nr. }\end{array}$ & $\begin{array}{l}\text { Desig- } \\
\text { nation }\end{array}$ & $\begin{array}{c}\text { Cement } \\
\text { (C) }\end{array}$ & $\begin{array}{l}\text { Recyclate } \\
\text { (R) }\end{array}$ & $\begin{array}{l}\text { Weight } \\
(\mathrm{C}+\mathrm{R})\end{array}$ & $\begin{array}{l}\text { Water } \\
\text { to mix } \\
\text { cement } \\
\text { putty } \\
\text { (V1) }\end{array}$ & $\begin{array}{l}\text { Water } \\
\text { added } \\
\text { to the } \\
\text { foam } \\
(\mathrm{V} 2)\end{array}$ & $\begin{array}{l}\text { Water } \\
(\mathrm{V} 1+\mathrm{V} 2)\end{array}$ & $\mathrm{w} / \mathrm{c}$ & foam & $\begin{array}{c}\text { Bulk } \\
\text { density }\end{array}$ \\
\hline & & {$[\mathrm{g}]$} & {$[\mathrm{g}]$} & {$[\mathrm{g}]$} & [g] & {$[\mathrm{ml}]$} & {$[\mathrm{ml}]$} & {$[-]$} & {$[\mathrm{ml}]$} & {$\left[\mathrm{kg} \cdot \mathrm{m}^{-3}\right]$} \\
\hline 45 & $\mathrm{C} 7.5 \mathrm{H}$ & 750.0 & 0.0 & 750 & 225 & 75 & 300 & 0.40 & 3.75 & 603.83 \\
\hline 40 & $\mathrm{C} 7.5 \mathrm{M}$ & 750.0 & 0.0 & 750 & 225 & 75 & 300 & 0.40 & 3.75 & 677.84 \\
\hline 29 & $\mathrm{C} 10 \mathrm{H}$ & 1000.0 & 0.0 & 1000 & 300 & 50 & 350 & 0.35 & 2.50 & 1333.10 \\
\hline 21 & C10M & 1000.0 & 0.0 & 1000 & 300 & 50 & 350 & 0.35 & 2.50 & 1394.40 \\
\hline 24 & $\mathrm{R} 7.5 \mathrm{H}$ & 487.5 & 262.5 & 750 & 225 & 75 & 300 & 0.40 & 3.75 & 1177.08 \\
\hline 34 & $\mathrm{R} 7.5 \mathrm{M}$ & 487.5 & 262.5 & 750 & 225 & 75 & 300 & 0.40 & 3.75 & 895.14 \\
\hline 15 & $\mathrm{R} 10 \mathrm{H}$ & 650.0 & 350.0 & 1000 & 300 & 50 & 350 & 0.35 & 2.50 & 1603.99 \\
\hline 12 & R10M & 650.0 & 350.0 & 1000 & 300 & 50 & 350 & 0.35 & 2.50 & 1457.30 \\
\hline 5 & RefC & 1000.0 & 0.0 & 1000 & 350 & 0 & 350 & 0.35 & 0.00 & 1646.10 \\
\hline 9 & RefR & 650.0 & 350.0 & 1000 & 385 & 0 & 385 & 0.39 & 0.00 & 1641.70 \\
\hline
\end{tabular}

TABle 1. Composition of the samples and the bulk density [5].

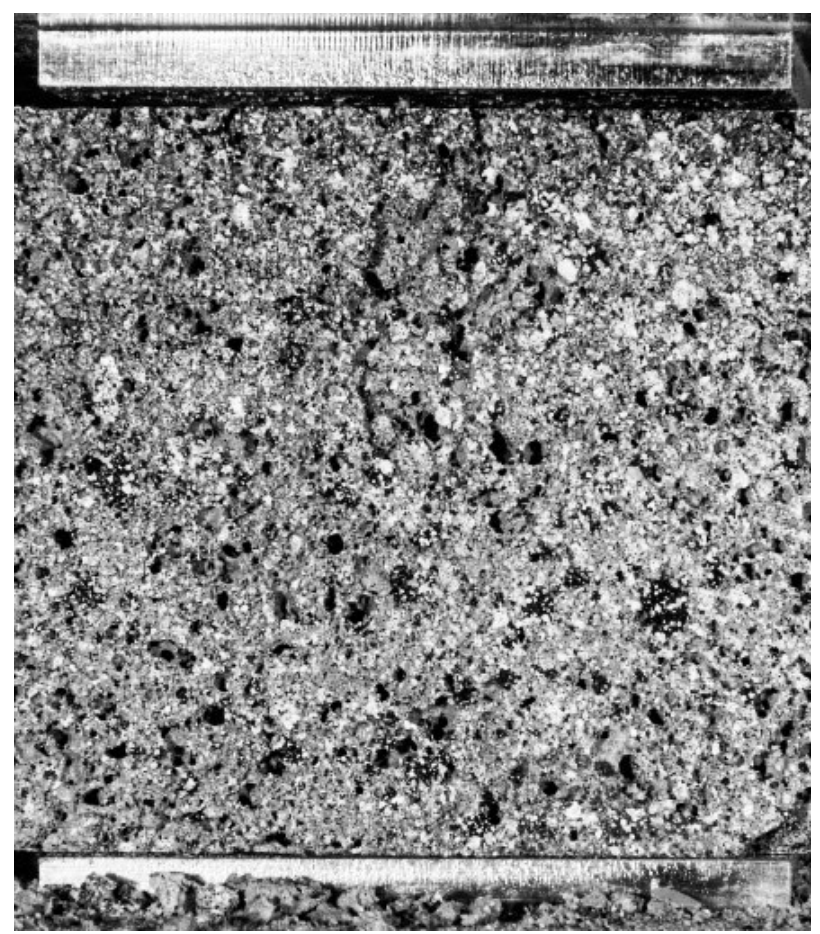

FigURE 1. Random pattern on a sample in grayscale.

hydraulic press Heckert model FP100, at a speed of $1 \mathrm{~mm}$ per minute. Subsequently, a static modulus of elasticity was specified. After that, static modulus of elasticity obtained on the basis of DIC analysis, static modulus of elasticity obtained on the basis of the displacement of the hydraulic press and the dynamic elastic modulus obtained by the ultrasonic and resonance method were compared. Nondestructive resonance method was used to measure dynamic modules. The Brüel \& Kjær measuring set consists of the

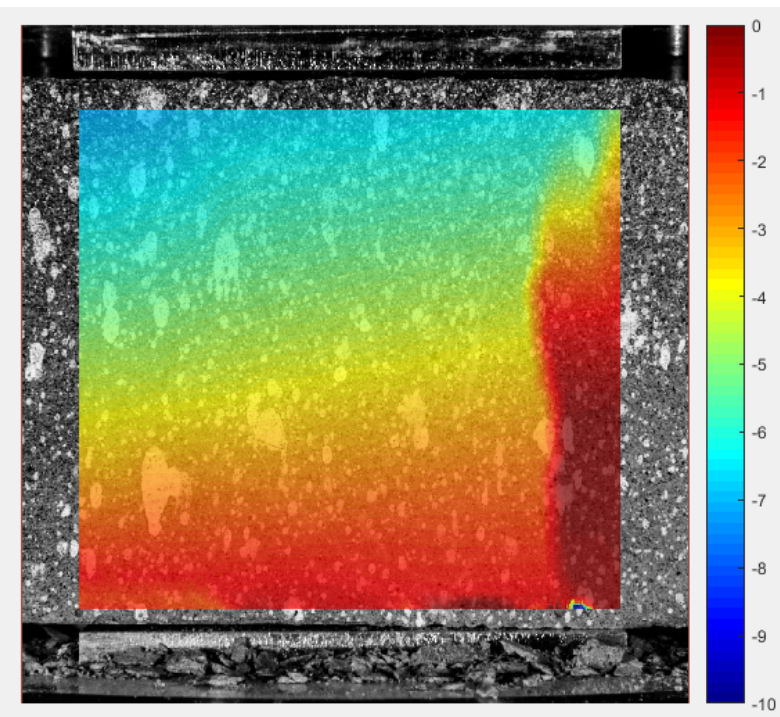

Figure 2. Field of vertical displacement from the Ncorr post software.

Brüel \& Kjær type 3560-B-120 measuring switchboard, the Brüel \& Kjær type 4519-003 acceleration sensor, the Brüel \& Kjær type 8206 impact hammer and the control laptop. Modulus of elasticity obtained from data from crosspiece of the hydraulic press does not correspond to the reality, because the deformation of the test instrument itself is included in the data. Also, the values of the dynamic modulus of elasticity are rather inaccurate due to the inappropriateness of the resonant and ultrasonic method on porous systems.

Dynamic modulus of elasticity should achieve higher values than static modulus of elasticity, because by non-destructive methods we get the tangent modulus 


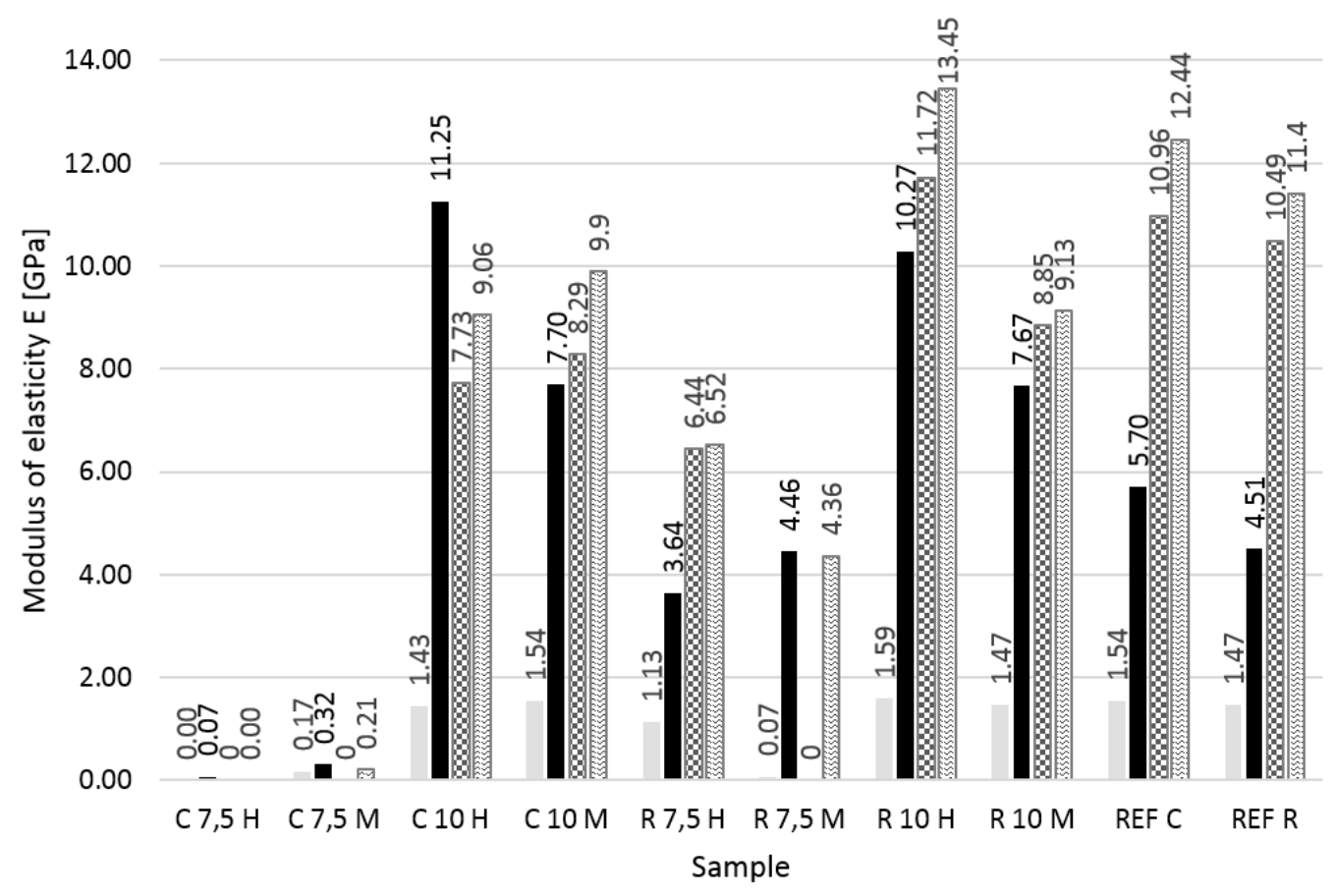

Estat press displacement [GPa] Estat DIC [GPa] Edyn resonance [GPa] 圈 Edyn ultrasound [GPa]

FIGURE 3. Results of static and dynamic moduli of elasticity.

of elasticity and the secant modulus of elasticity we get from the loading test [6].

\section{PRINCIP OF DIC ANALYSiS}

DIC (Digital Image Correlation) is an optical method used to measure displacement on the sample surface. Compares the grayscale values of individual groups of points called subsets on the surface of the sample between the pictures taken during the loading test. It is necessary to have a sufficiently contrasting random pattern on the surface of the sample. Some materials have this pattern naturally. For other samples, the pattern should be applied appropriately. The software compares shades of gray and their displacement between individual photos (Figure 11). The result is the field of displacement between the reference and each picture. The reference picture is usually taken before the start of the test [7, 8].

\section{Advantages of DiC analysis}

DIC analysis is a cost-effective optic method that can be used in laboratory and outdoor environment. It is used to inspect large important structures (bridges, industrial buildings, power plants) that degrade due to external influences. The capture of large objects can be done directly from the air using drones thanks to advanced technologies. This solution is relatively simple, accurate and financially advantageous [1, 2].

During the measurements in the laboratory, we obtain a field of displacement in the horizontal and vertical directions. We can also measure cracks occurring. During the loading tests, the exact course of cracks can be determined by DIC analysis, even those that are not observable by the naked eye. These data are very beneficial for the presumption of the durability of the tested material [2].

\section{SAMPle MeASUREMENT}

DIC analysis was used on foamed cement paste samples. Half of cement paste beams were tested according to CSN EN 12390-3 Test of hardened concrete - Part 3: Compressive strength of test samples [9. A random contrast pattern of black and white spray was applied to the samples. During the testing, images were taken with Canon EOS $70 D$ on a tripod from a distance of approximately 300 millimeters. The images were taken in a one-second sequence during loading. For each sample, $50-100$ photos were taken. The photos were edited in Adobe Lightroom for higher contrast, and then the DIC analysis was performed in Ncorr version 1.2.1. The results were scaled and the virtual extensometer was placed in the field of displacement in the ncor_post software (Figure 2). The results of the individual displacement were assigned to the respective forces using the extractForces software. Subsequently, a static modulus of elasticity in Microsoft Excel was calculated from the results.

\section{RESUlts AND DisCUSSIONS}

Samples Ref $\mathrm{C}$ and Ref $\mathrm{R}$ were references. The other eight samples were differently foamed. Samples 
C $7.5 \mathrm{H}, \mathrm{C} 7.5 \mathrm{M}$, and $\mathrm{R} 7.5 \mathrm{M}$ were foamed too much therefore it was not possible to measure the dynamic modulus of elasticity by the resonance method because it was not possible to capture the response from the impact hammer. The results of the other modulus of elasticity in these three samples, because of their high foaming, are not very accurate. In the case of the compression test, these three samples were observed (especially for samples C 7.5 H and C 7.5 M), as the material collapsed successively on the floors. It was not about the flexible behavior that is assumed to acquire the modulus of elasticity. Therefore, the results of the measurements of these samples should be considered inaccurate, and due to their poor mechanical properties, do not use this highly foaming cement paste for practical use in the building industry.

The static modulus of elasticity for all samples obtained from the displacement of the hydraulic press crosspiece are very low. This is due to the deformation of the test rig itself together with the sample deformation. For this reason, it makes no sense to further consider the static modulus of elasticity thus obtained.

Measurement of C $10 \mathrm{M}, \mathrm{R} 10 \mathrm{H}$ and R $10 \mathrm{M}$ samples were expected, static moduli of elasticity are slightly less than dynamic. For samples R $7.5 \mathrm{H}$, Ref $\mathrm{C}$, and Ref $\mathrm{R}$, the static moduli of elasticity are approximately half that of the dynamic moduli of elasticity. On the other hand, the static modulus of elasticity is higher than the dynamic for $\mathrm{C} 10 \mathrm{H}$ sample (Figure 3). This is due to the inaccuracy of measuring the dynamic modulus of elasticity because of the inappropriateness of the resonant and ultrasonic method on porous systems.

\section{Conclusion}

For this type of samples, the most accurate method is DIC analysis. Measurement by ultrasonic method or resonance method is not accurate in porous systems. Measurement of deformation directly from the hydraulic device is very inaccurate as it involves deformation of the hydraulic device itself.

The results show that the less or no foamed samples without recyclate have a higher modulus of elasticity than samples with recyclate, but with more foamed samples, it is the opposite. Furthermore, it is noticeable that the less foamed samples with a foaming additive used by firefighters have a higher modulus of elasticity than samples with a foaming additive for industrial use, but with more foamed samples, this is the opposite.

\section{ACKNOWLEDGEMENTS}

This outcome was supported by the Czech Technical University in Prague under No. SGS16/201/OHK1/3T/11 and No. SGS17/060/OHK1/1T/11 and by the Ministry of Education, Youth and Sports within National Sustainability Programme I, project No. LO1605. The authors also thank the Center for Nanotechnology in Civil Engineering at the Faculty of Civil Engineering, Czech Technical University in Prague, and the Joint Laboratory of Polymer Nanofiber Technologies of the Institute of Physics, Academy of Science of Czech Republic, and the Faculty of Civil Engineering, Czech Technical University in Prague.

\section{REFERENCES}

[1] P. K. Rastogi, E. Hack. Optical methods for solid mechanics: a full-field approach. John Wiley \& Sons, 2012.

[2] N. McCormick, J. Lord. Digital image correlation. Materials today 13(12):52-54, 2010.

[3] Jasar. Optické vady a vlastnosti objektivu. http: //photo.mysteria.cz/clanky/objekt2.html\#aberace 2002.

[4] L. Jelinek. Darktable: Korekce objektivu a odstranění skvrn. https://www.linuxexpres.cz/praxe/ darktable-korekce-objektivu-a-odstraneni-skvrn, 2015 .

[5] V. Růžička. Mechanické vlastnosti pěnových cementových pas. Master's thesis, Czech technical university in Prague, Prague, 2017.

[6] M. Ballon. Porovnani moduli pružnosti stavebních materiali. Master's thesis, Brno University of Technology. Faculty of Civil Engineering, Brno, 2014.

[7] M. A. Sutton, J. J. Orteu, H. Schreier. Image correlation for shape, motion and deformation measurements: basic concepts, theory and applications. Springer Science \& Business Media, 2009.

[8] S. Yoneyama, G. Murasawa. Digital image correlation. Experimental Mechanics 2009.

[9] ČSN EN 12390-3-Zkoušení ztvrdlého betonu-Část 3: Pevnost v tlaku zkušebních těles. Úřad pro technickou normalizaci, metrologii a zkušebnictví 10, 2009. 